TẠP CHÍ Y HỌC VIẸT NAM TẬP 502 - THÁNG 5 - SÓ 2 - 2021

\begin{tabular}{|c|c|c|c|c|c|c|}
\hline án) ( $\mathrm{n}=45)$ & & & & & & \\
\hline Đà Năng (Dự án) $(\mathrm{n}=71)$ & 39,51 & 23,38 & 1,10 & 8,36 & 14,07 & 0.00 \\
\hline Hải Dương $(\mathrm{n}=37)$ & 23,21 & 32,68 & 10,89 & 10,85 & 0.00 & 13,19 \\
\hline Tiền Giang $(\mathrm{n}=8)$ & 39,35 & 44,30 & 2,52 & 0,00 & 0.00 & 4,54 \\
\hline Giới: Nam $(\mathrm{n}=61)$ & 37,00 & 33,73 & 7,71 & 8,58 & 7,32 & 2,29 \\
\hline Nữ ( $\mathrm{n}=55)$ & 30,54 & 24,56 & 1,21 & 7,52 & 7,43 & 7,46 \\
\hline Bậc học & & & & & & \\
\hline Tiếu học $(\mathrm{n}=55)$ & 32,34 & 30,74 & 1,12 & 6,88 & 5,58 & 0,76 \\
\hline Trung học cơ sở $(\mathrm{n}=61)$ & 35,37 & 28,14 & 7,79 & 9,15 & 8,99 & 9,03 \\
\hline Khu vực & & & & & & \\
\hline Thành thị $(\mathrm{n}=93)$ & 33,37 & 23,01 & 0,87 & 7,86 & 11,18 & 0,55 \\
\hline Nông thôn $(\mathrm{n}=23)$ & 35,02 & 41,71 & 11,90 & 8,50 & 0.00 & 13,95 \\
\hline
\end{tabular}

\section{KẾT LUÂ̂N}

Kiến thức, thái độ và thực hành của học sinh tiểu học và trung học cơ sở liên quan đến tật khúc xạ và sức khoẻ mắt còn ở mức khá khiêm tốn, đòi hỏi cần tăng cường hoạt động truyền thông về chăm sóc mắt góp phần cải thiện kiến thức, thái độ và thực hành cho nhóm đối tượng trên. Ngoài ra có thể phát triển tài liệu giảng dạy kiến thức, thái độ và thực hành về tật khúc xạ và chăm sóc mắt liền quan đến phòng tránh, điều chỉnh tật khúc xạ nhằm vào nhóm đối tượng học sinh tiểu học và trung học cơ sở.

\section{TÀI LIỆU THAM KHẢO}

1. Paudel, P., Ramson, P., Naduvilath, T.,
Wilson, D., Phuong, H. T., Ho, S. M., \& Giap, N. V. (2014). Prevalence of vision impairment and refractive error in school children in Ba RiaVung Tau province, Vietnam. Clinical \& experimental ophthalmology, 42(3), 217-226.

2. Agarwal, R. \& Dhoble, P.' (2013). Study of the Knowledge, Attitude and Practices of Refractive Error with Emphasis on Spectacle Usages in Students of Rural Central India. Journal of Biomedical and Pharmaceutical Research, 2(3), 150-154

3. J A Ebeigbe, F Kio, L I Okafor (2013). Attitude and Beliefs of Nigerian Undergraduates to Spectacle Wear. Ghana Med J. ; 47(2): 70-73.

4. Lê Thị Thanh Xuyên, Bùi Thị Thu Hương, Phí Duy Tiến (2009). Prevalence of Refractive error and Knowledge, Attitudes and Self Care Practices Associated with Refractive Error in Ho Chi Minh City. Y Hoc TP. Ho Chi Minh. 13(1). 13-25.

\title{
ĐÁNH GIÁ KẾT QUẢ ĐIỀU TRİ BỆNH MÀNG TRONG Ở TRẺ SƠ SINH NON THÁNG BẰNG LIỂU PHÁP SURFACTANT TẠI BỆNH VIỆN SẢN-NHI TỈNH QUẢNG NGÃI
}

\section{TÓM TẮT}

Đặt vấn đề: Bệnh màng trong hay còn gọi là Hội chứng suy hô hấp là bệnh lý khá phổ biến ở trẻ sớ sinh, đặc biệt ở trẻ sơ sinh non tháng, nguyên nhân là do thiếu chất hoạt diện (Surfactant) ở phổi. Tại Bệnh viện Sản-Nhi Quảng Ngãi, Surfactant ngoai sinh đã được đưa vào sử dụng từ lâu, tuy nhiên việc điều trị đa phân chưa đạt kết quả cao. Chúng tôi mong muốn đánh giá kết quả sử dụng liệu pháp Surfactant thay thế trong điều trị Bệnh màng trong. Mục tiêu: Mô tả đặc điểm lâm sàng, cận lâm sàng và một số yếu tố liển quan về Bệnh màng trong ở trẻ sơ sinh non tháng. Đánh giá kết quả điều trị Bệnh màng trong ở

${ }^{1}$ Bệnh viện Sản-Nhi tỉnh Quảng Ngãi

Chịu trách nhiệm chính: Nguyển Đình Tuyến

Email: nguyendinhtuyen889@gmail.com

Ngày nhận bài: 2.3.2021

Ngày phản biên khoa học: 27.4.2021

Ngày duyệt bài: 11.5.2021

\section{Phạm Vân Anh ${ }^{1}$, Nguyễn Đình Tuyến ${ }^{1}$}

trẻ sơ sinh non tháng bằng liệu pháp Surfactant. Đối tượng và phương pháp nghiên cứu: Nghiên cứu cắt ngang mô tả, hồi cứu toàn bô hồ sơ bệnh án của trẻ sơ sinh non tháng được chẩn đoán Bệnh màng trong, chỉ định điều trị thay thế bằng Surfactant tại khoa Sơ sinh, Bệnh viện Sản-Nhi Quảng Ngãi từ 01/01/2019 đến 30/06/2020. Kết quả: Tỷ lệ nam/nữ là $1 / 1,1$; tuổi thai rất non $<32$ tuần là $63,2 \%$, trung bình 30,1 3,1 tuần; cân nặng chủ yếu <2000 gr chiếm 73,6\%, cân nặng lúc sinh trung bình là $1521 \pm$ 588 gr. Các dấu hiệu suy hô hấp xuất hiện sớm, có $47,4 \%$ trẻ được hồi sức đă̆t nội khí quản lúc nhập khoa, thở rên $(60 \%)$, hạ thẩn nhiệt $(71,9 \%)$, rối loạn nhịp thở $(63,3 \%)$, tím $(40,4 \%)$. pH giảm nặng dưới 7,25 chiếm $56,1 \%$, giảm oxy hóa máu từ nhẹ đến nặng là $82,5 \%$. Tổn thương trên Xquang phổi độ II-III chiếm $77,2 \%$. Giới tính là liên quan có ý nghĩa thống kê với mức độ nặng của Bệnh màng trong trên Xquang. Surfactant có hiệu quả rõ rệt khi nhu câu Oxy và tình trang toan hô hấp máu được cải thiện nhanh chóng sau bơm 1 giờ. X-quang phổi cải thiện $96,5 \%$ 
sau 6 giờ. Thời gian thở máy trung bình là 3 ngày, thở máy không xâm nhập là 6 ngày. Trẻ sống chiếm $80 \%$; biến chứng trong 24 giờ sau bơm nhiều nhất là hạ huyết áp $(15,8 \%)$. nguyên nhân chính là sốc do nhiễm trùng huyết $(58,3 \%)$. Kết luận: Điều trị Surfactant thay thế ở trẻ sơ sinh non tháng bị Bệnh màng trong tại Bệnh viện Sản-Nhi Quảng Ngãi đem lại hiệu quả rõ rệt, giảm nhu câu Oxy sau bơm thuốc 1 giờ, Xquang phổi cải thiện $96,5 \%$ sau 6 giờ bơm thuốc.

Tư khóa: Bệnh màng trong, trẻ sơ sinh non tháng, BV Sản-Nhi tỉnh Quảng Ngã̃i

\section{SUMMARY \\ EVALUATION OF THE EFFECT OF SURFACTANT THERAPY IN PREMATURE INFANTS WITH HYALINE MEMBRANE AT QUANG NGAI HOSPITAL FOR CHILDREN AND WOMEN}

Background: Hyaline Membrane Disease, also known as Respiratory Distress Syndrome, is a fairly common condition in infants, especially preterm neonates, due to the lack of active substances (Surfactant) in the lungs. Exogenous Surfactant has been used for a long time, but most of the treatment has not achieved high results at Quang Ngai Hospital for Children and Women. We want to evaluate the effect of this therapy to draw on the experience and improve the quality of Surfactant replacement therapy in Hyaline Membrane Disease. Objectives: Describe clinical, subclinical characteristics and some related factors to premature infants with Hyaline Membrane Disease and its result treated with Surfactant therapy. Methods: Cross-sectional study, descriptive, retrospective entire medical records of preterm neonates with Hyaline Membrane Disease, with indications Surfactant therapy at Quang Ngai Hospital for Children and Women from January 1st, 2019 to June 30th, 2020. Results: Male/female ratio is similar $(1 / 1,1)$; gestational age $<32$ weeks is $63,2 \%$, with a mean of $30,1 \pm 3,1$ weeks; the birth weight $<2000$ grams is $73,6 \%$, with a mean of $1521 \pm 588$ grams. Among the signs of respiratory distress appear early, intubated resuscitation at hospital admission is $47,4 \%$, grunting $(60 \%)$, hypothermia $(71,9 \%)$, breathing disorders $(63,3 \%)$, purple $(40,4 \%)$. pH dropped below 7,25 accounts for $56,1 \%$, reducing oxidation of blood from mild to severe is $82,5 \%$. Lesions on lung X-ray II-III level accounts for $77,2 \%$. Only sex is associated with statistical significance with the severity of the disease on X-ray film. Surfactant replacement therapy is remarkably effective when oxygen demand and respiratory acidosis conditions are rapidly improved after pumped 1 hour. X-ray lesions improve 96,5\% after 6 hours of Surfactant pump. The mean mechanical ventilation duration is three days and the mean non-invasive mechanical ventilation duration is six days. The survival rate and the mortality rates after Surfactant therapy are $80 \%$ and $20 \%$, respectively; The most complication within 24 hours after pumping is hypotension $(15,8 \%)$, leading cause is a septic shock $(58,3 \%)$. Conclusion: Surfactant replacement therapy in preterm neonates with Hyaline Membrane Disease at Quang Ngai Hospital for Children and Women brings a marked effect, reduces the oxygen demand after 1 hour of pumping, and improves $96.5 \%$ chest X-ray after 6 hours of pumping.

\section{I. Đă̆T VẤN ĐỀ}

Bệnh màng trong là do thiếu chất hoạt diện bề mặt ở phổi. Chiếm 1\% ở trẻ sơ sinh, $10 \%$ ở tất cả trẻ sơ sinh đẻ non, và $50 \%$ ở trẻ đẻ non trước 30 tuân thai. Tỷ lệ ghi nhận bệnh màng trong ở trẻ đủ tháng khoảng $5 \%$ và rất hiếm ở những thai kỳ trên 38 tuân. Tỉ lệ tử vong ở trẻ sơ sinh non tháng khá cao khoản 30\% [4],[6]. Trước đây, chúng tôi điêu trị kết quả không cao, hâu hết là chuyển tuyến. Chúng tôi mong muốn đánh giá hiệu quả điều trị của liệu pháp Surfactant thay thế để giảm tỷ lệ tử vong ở trẻ sơ sinh non tháng. Mục tiêu:

1. Mô tả đặc điểm lâm sàng, cận lâm sàng và một số yếu tố liên quan về bệnh màng trong ở trẻ sơ sinh non tháng.

2. Đánh giá kêt quả điều trị bệnh màng trong ơ trẻ so sinh non tháng bằng liệu pháp Surfactant.

\section{II. ĐỐI TƯƠNG VÀ PHƯƠNG PHÁP NGHIÊN CỨU \\ Phương pháp: cắt ngang mô tả}

Đối tượng nghiên cứu: gồm 57 bệnh nhi sơ sinh được điều trị bơm Surfactant tại khoa Nhi Sơ sinh, Bệnh viện Sản Nhi tỉnh Quảng Ngãi từ 01/01/2019 - 30/06/2020.

Tiêu chuẩn chọn bệnh: Hồ sơ bệnh án của tất cả trẻ sơ sinh non tháng được chẩn đoán bệnh màng trong, có chỉ định dùng Surfactant.

Tiêu chuẩn loại trừ: Hồ sơ bệnh án không đủ chuẩn theo thiết kế.

-Ghi nhận một số yếu tố tiên sử mẹ và trẻ: tuổi thai, cân nặng lúc sinh, phương pháp sinh, APGAR 5 phút, hồi sức sau sinh,...đặc điểm lâm sàng: rối loạn tri giác, điểm Silvermann, cơn ngưng thở, sinh hiệu, FiO2, X-Quang ngực, khí máu động mạch trước và sau bơm Surfactant; mức độ và thời gian hỗ trợ hô hấp, liêu Surfactant, tai biến - biến chứng; kết quả điêu trị.

Xử lý số liệu: phần mềm SPSS 20.0.

\section{KẾT QUẢ NGHIÊN CỨU}

\section{1. Đăc điểm chung}

Bảng 1. Đặc đîểm chung của nhóm trẻ so sinh

\begin{tabular}{|c|c|c|c|}
\hline \multicolumn{2}{|c|}{ Đặc điểm } & Tân số (n=57) & Tỷ lệ \% \\
\hline \multirow{2}{*}{ Giới } & Nam & 27 & 47,4 \\
\cline { 2 - 4 } & Nữ & 30 & 52,6 \\
\hline $\begin{array}{c}\text { Tuối thai } \\
\text { (tuân) }\end{array}$ & $30,1 \pm 3,1^{*}$ & $24-36 * *$ \\
\hline \multicolumn{2}{|c|}{ Cân nặng lúc sinh(gr) } & $1521,9 \pm 588,0 *$ & $600-2800^{* *}$ \\
\hline
\end{tabular}

Nhận xét: Tỷ lệ trẻ sơ sinh nữ và nam tương 
đương (52,6\% và 47,4\%). Tuổi thai trung bình là $30,1 \pm 3,1$ tuân.

Bảng 2. Đăc điểm tiền căn của nhóm trẻ so sinh

\begin{tabular}{|c|c|c|c|}
\hline \multicolumn{2}{|c|}{ Đặc điểm } & $\begin{array}{l}\text { Tân số } \\
(n=57)\end{array}$ & Tỷ lệ \\
\hline \multirow{2}{*}{$\begin{array}{l}\text { APGAR 5' } \\
\quad<7 đ\end{array}$} & Có & 7 & 12,3 \\
\hline & Không & 50 & 87,7 \\
\hline \multirow{2}{*}{$\begin{array}{l}\text { Phương } \\
\text { pháp sinh }\end{array}$} & Sinh thường & 30 & 52,6 \\
\hline & Sinh mố & 27 & 47,4 \\
\hline \multirow{6}{*}{$\begin{array}{l}\text { Hồi sức } \\
\text { sau sinh }\end{array}$} & Thở oxy & 12 & 21,1 \\
\hline & Bóp bóng mask & 37 & 64,9 \\
\hline & Đặt Nội khí quản & 24 & 42,1 \\
\hline & $\begin{array}{l}\text { Xoa bóp tim ngoài } \\
\text { lồng ngực }\end{array}$ & 4 & 7,0 \\
\hline & Adrenaline & 7 & 12,3 \\
\hline & Không hồi sức & 12 & 21,1 \\
\hline
\end{tabular}

Nhân xét: Tỷ lệ sinh ngạt là 12,3\%. Có 45 ca cân hồi sức sau sinh, hầu hết cần can thiệp phương pháp bóp bóng (64,9\%).

Bảng 3: Đặc điểm tiên căn mẹ

\begin{tabular}{|c|c|c|}
\hline Đắc điểm & $\begin{array}{c}\text { Tân số } \\
(\mathbf{n}=\mathbf{5 7})\end{array}$ & $\begin{array}{c}\text { Tỷ lệ } \\
\mathbf{0}\end{array}$ \\
\hline Tiêm corticoid trước sinh & 12 & 21,1 \\
\hline Tăng huyết áp mạn/ thai kỳ & 5 & 8,8 \\
\hline Öi vỡ sớm > 18 giờ & 3 & 5,3 \\
\hline $\begin{array}{c}\text { Viêmm nhiêm niệu dục trong } \\
\text { thai kỳ không điều trị }\end{array}$ & 1 & 1,8 \\
\hline Sinh non & 3 & 5,3 \\
\hline Sấy thai & 10 & 17,5 \\
\hline
\end{tabular}

Nhận xét: Chỉ có $21,1 \%$ các bà mẹ được tiêm corticoid trước sinh.

2. Đặc điểm lâm sàng, cận lâm sàng và môtt số yếu tố liên quan đến Bềnh màng trong

Bảng 4. Đăc điểm lâm sàng trước bơm Surfactant

\begin{tabular}{|c|c|c|c|}
\hline \multicolumn{2}{|c|}{ Đặc điểm } & $\begin{array}{c}\text { Tân số } \\
\text { (n=57) }\end{array}$ & $\begin{array}{c}\text { Tỷ lệ } \\
\text { \%o }\end{array}$ \\
\hline \multirow{2}{*}{ Ngưng thở } & Không & 28 & 49,1 \\
\cline { 2 - 4 } & Có & 2 & 3,5 \\
\cline { 2 - 4 } & Không đánh giá & 27 & 47,4 \\
\hline
\end{tabular}

\begin{tabular}{|c|c|c|c|}
\hline \multirow{3}{*}{ Thở rên } & Không & 12 & 21,1 \\
\cline { 2 - 4 } & Có & 18 & 31,6 \\
\cline { 2 - 4 } & Không đánh giá & 27 & 47,4 \\
\hline \multirow{2}{*}{$\begin{array}{c}\text { Rút lõm } \\
\text { lông ngực }\end{array}$} & Không & 11 & 19,3 \\
\cline { 2 - 4 } & Có & 19 & 33,3 \\
\cline { 2 - 4 } & Không đánh giá & 27 & 47,4 \\
\hline \multirow{3}{*}{$\begin{array}{c}\text { Nhịp thở } \\
\text { (lầ/phút) }\end{array}$} & $<30$ & 0 & 0,0 \\
\cline { 2 - 4 } & $30-<60$ & 19 & 33,3 \\
\cline { 2 - 4 } & $\geq 60$ & 11 & 19,3 \\
\hline \multirow{2}{*}{ Nhiệt độ } & Háp bóng thân nhiệt & 27 & 47,4 \\
\cline { 2 - 4 } & Bình thường & 16 & 71,9 \\
\hline \multirow{2}{*}{ SpO2 (\%) } & $<90$ & 23 & 40,4 \\
\cline { 2 - 4 } & $\geq 90$ & 34 & 59,6 \\
\hline \multirow{3}{*}{ FiO2 (\%) } & $<30$ & 5 & 8,8 \\
\cline { 2 - 4 } & $30-<40$ & 18 & 31,6 \\
\cline { 2 - 4 } & $\geq 40$ & 34 & 59,6 \\
\hline
\end{tabular}

Nhân xét; có 27 trẻ đã được hỗ trợ với đặt nội khí quản bóp bóng lúc nhập khoa; 3,5\% có cởn ngưng thở bệnh lý; Hạ thân nhiệt chiếm $71,9 \%$.

Bảng 5: Đăc điểm cận lâm sàng trước bơm Surfactaint

\begin{tabular}{|c|c|c|c|}
\hline \multicolumn{2}{|c|}{$\begin{array}{c}\text { Đặc điểm cận lâm } \\
\text { sàng }\end{array}$} & $\begin{array}{c}\text { Tân số } \\
(n=57)\end{array}$ & $\begin{array}{l}\text { Tỷ lệ } \\
(\%)\end{array}$ \\
\hline \multirow{3}{*}{$\begin{array}{c}\text { Trên } \\
\text { phim } \\
\text { Xquang }\end{array}$} & Độ II & 16 & 28,1 \\
\hline & Độ III & 28 & 49,1 \\
\hline & Độ IV & 13 & 22,8 \\
\hline \multirow{3}{*}{$\mathrm{pH}$} & $<7,25$ & 32 & 56,1 \\
\hline & $7,25-7,45$ & 23 & 40,4 \\
\hline & $>7,45$ & 2 & 3,5 \\
\hline \multirow{3}{*}{$\begin{array}{c}\mathrm{pCO} 2 \\
(\%)\end{array}$} & $<35$ & 18 & 31,6 \\
\hline & $35-45$ & 17 & 29,8 \\
\hline & $>45$ & 22 & 38,6 \\
\hline \multirow{3}{*}{$\begin{array}{l}\text { Giảm } \\
\text { oxy hóa } \\
\text { máu }\end{array}$} & Bình thường & 10 & 17,5 \\
\hline & Nhẹ & 33 & 57,9 \\
\hline & Nặng & 14 & 24,6 \\
\hline
\end{tabular}

Nhân xét: Xquang găp nhiều nhất là độ III chiếm 49,1\%; khí máu trước bơm: $56,1 \%$, mức $\mathrm{pCO}_{2}$ cao trên 45 mmHg chiếm 38,6\%.

3. Một số yếu tố liên quan đến mức độ nặng của Bệnh màng trong

Bảng 6: Liên quan giữa giới tính trẻ và mức độ nặng của bệnh màng trong

\begin{tabular}{|c|c|c|c|c|c|c|}
\hline \multirow{3}{*}{\multicolumn{2}{|c|}{ Đặc điểm }} & \multicolumn{4}{|c|}{ Mức độ nặng của bệnh màng trong } & \multirow{3}{*}{$\mathbf{p}$} \\
\hline & & \multicolumn{2}{|c|}{ Độ II } & \multicolumn{2}{|c|}{ Độ III-IV } & \\
\hline & & $\mathbf{n}$ & $\%$ & $\mathbf{n}$ & $\%$ & \\
\hline \multirow{2}{*}{ Giới tính trẻ } & Nam & 4 & 14,8 & 23 & 85,2 & \multirow{2}{*}{0,04} \\
\hline & Nữ & 12 & 40,0 & 18 & 60,0 & \\
\hline \multirow{2}{*}{$\begin{array}{l}\text { Mẹ điêu trị Corticoid } \\
\text { trước sinh }\end{array}$} & Có & 6 & 50,0 & 6 & 50,0 & \multirow{2}{*}{$0,08 * * *$} \\
\hline & Không & 10 & 22,2 & 35 & 77,8 & \\
\hline \multicolumn{2}{|c|}{ Tuối thai (tuần)* } & \multicolumn{2}{|c|}{$31,2 \pm 2,7$} & \multirow{2}{*}{\multicolumn{2}{|c|}{$\frac{29,7 \pm 3,2}{13000}$}} & 0,1 \\
\hline \multicolumn{2}{|c|}{ Cân nặng lúc sinh $(\mathrm{gr})^{* *}$} & \multicolumn{2}{|c|}{1445,0} & 1300,0 & & 0,12 \\
\hline
\end{tabular}

*Trung bình \pm độ lệch chuẩn **Trung vị, GTLN-GTNN ****Test Fisher với độ tin cậy $\mathrm{p}<0,05$

Nhận xét: tỷ lệ điều trị dự phòng corticoid trước sinh $(50,0 \%)(p=0,08)$. 
Bảng 7: Liên quan đến kêt quả điều trị

\begin{tabular}{|c|c|c|c|}
\hline Đặc điếm & Sống $(\mathbf{n = 4 5})$ & Tử vong $(\mathbf{n = 1 2})$ & $\mathbf{p}$ \\
\hline Tuối thai (tuần) & 31 & 27,5 & 0,00 \\
\hline Cân nắng lúc sinh $(\mathrm{gr})$ & 1450 & 1050 & 0,00 \\
\hline FiO2 lúc nhập khoa (\%) & 30 & 45 & 0,03 \\
\hline
\end{tabular}

Nhận xét: Nhóm tử vong có tuổi thai và cân nặng lúc sinh thấp hơn nhóm sống, $\mathrm{FiO}_{2}$ lúc nhập khoa cao hơn nhóm sống.

4. Diễn tiến quá trình điều trị Surfactant

Bảng 8: Diễn tiến điều trị Surfactant

\begin{tabular}{|c|c|c|c|}
\hline \multicolumn{2}{|c|}{ Diên tiến điếu trị } & \multirow{3}{*}{$\begin{array}{c}\text { Tân số } \\
3 \\
179,9 \pm 38,5\end{array}$} & \multirow{3}{*}{$\begin{array}{c}\text { Tỷ lệ (\%) } \\
1-28 \\
109-270\end{array}$} \\
\hline Thời gian bơm lế & 1 (giờ)* & & \\
\hline \multirow{2}{*}{ Liều bơm Surfactant $(\mathrm{mg} / \mathrm{kg} / \mathrm{lần})^{* *}$} & Lần 1 & & \\
\hline & Lần 2 & $134,0 \pm 36,2$ & $83-200$ \\
\hline \multirow{2}{*}{ Hỗ trợ hô hấp trước bơm lần 1} & NCPAP & 24 & 42,1 \\
\hline & Thở máy & 33 & 57,9 \\
\hline \multirow{3}{*}{ Bơm Surfactant lần 1} & Thở máy & 39 & 68,4 \\
\hline & INSURE thành công & 11 & 19,3 \\
\hline & INSURE thất bai & 7 & 12,3 \\
\hline \multirow{3}{*}{ Hiệu quả sau bơm Surfactant lần 1} & Đáp ứng hoàn toàn & 42 & 73,7 \\
\hline & Đáp ứng không hoàn toàn & 7 & 12,3 \\
\hline & Không đáp ứng & 8 & 14,0 \\
\hline \multirow{2}{*}{ Hiệu quả sau bơm Surfactant lần 2} & Đáp ứng hoàn toàn & 4 & 57,1 \\
\hline & Không đáp ứng & 3 & 42,9 \\
\hline \multirow{2}{*}{$\begin{array}{l}\text { Loại tai biến sau bơm Surfactant } \\
\qquad(n=11)\end{array}$} & Ha huyết áp & 9 & \\
\hline & Xuất huyết phối & 3 & \\
\hline \multirow{2}{*}{$\begin{array}{l}\text { Cải thiên tốn thương trên } \\
\text { X-Quang trước và sau bơm } 6 \mathrm{~h}\end{array}$} & Cải thiện & 55 & 96,5 \\
\hline & Không cải thiện & 2 & 3,5 \\
\hline \multirow{2}{*}{ Hỗ trợ hô hấp } & NCPAP/NIPPV & 6 & $0-35$ \\
\hline & Thở máy & 3 & $0-39$ \\
\hline \multirow{8}{*}{ Biến chứng } & Sốc & 11 & 19,3 \\
\hline & Nhiêm trùng huyết sớm & 15 & 26,3 \\
\hline & Nhiêm trùng huyết muộn & 18 & 31,8 \\
\hline & Rối loạn đông máu & 20 & 35,1 \\
\hline & Viêm ruột hoại tứ & 3 & 5,3 \\
\hline & Bệnh phối mạn & 1 & 1,8 \\
\hline & Xuất huyết não & 15 & 26,3 \\
\hline & Ha HA & 9 & 15,8 \\
\hline \multirow{3}{*}{ Kết quả } & Xuất viện & 36 & 63,2 \\
\hline & Tử vong & 12 & 21,0 \\
\hline & Chuyến viện & 9 & 15,8 \\
\hline Thời gian nằm viện (ngày)* & & 20,0 & $1-72$ \\
\hline
\end{tabular}

* Trung vi - GTNN-GTLN **Trung bình - GTLN-GTNN

Nhận xét: Thời gian bơm Surfactant trung vị là 3 giờ. Có 8 ca không đáp ứng, chiếm 14,0\%; bơm Surfactant lần 2; 28,6\% (3/7) ca không đáp ứng

Bảng 9: Thay đồi FiO2, SpO2, pH và pCO2 trước và sau bơm Surfactant

\begin{tabular}{|c|c|c|c|}
\hline \multicolumn{2}{|c|}{ Đắc điếm } & Kết quả & p \\
\hline \multirow{3}{*}{$\begin{array}{c}\text { FiO2 } \\
\text { (\%) }\end{array}$} & Trước bơm & 40 & - \\
\cline { 2 - 4 } & Sau bơm 1h & 25 & 0,00 \\
\cline { 2 - 4 } & Sau bơm 6h & 21 & 0,00 \\
\cline { 2 - 4 } & Sau bơm 24h & 21 & 0,00 \\
\hline \multirow{3}{*}{$\begin{array}{c}\text { SpO2 } \\
\text { (\%) }\end{array}$} & Trước bơm & 91,0 & - \\
\cline { 2 - 4 } & Sau bơm 1h & 96,0 & 0,00 \\
\cline { 2 - 4 } & Sau bơm 6h & 96,5 & 0,00 \\
\cline { 2 - 4 } & Sau bơm 24h & 97,0 & 0,00 \\
\hline
\end{tabular}

\begin{tabular}{|c|c|c|c|}
\hline \multirow{2}{*}{$\mathrm{pH}$} & Trước bơm & 7,24 & \multirow{2}{*}{0,00} \\
\cline { 2 - 3 } & Sau bơm 1h & 7,29 & \\
\hline \multirow{2}{*}{ pCO2 } & Trước bơm & 39 & \multirow{2}{*}{0,04} \\
\cline { 2 - 3 } & Sau bơm 1h & 38 & 0 \\
\hline
\end{tabular}

Nhân xét: pCO2 sau bơm giảm hơn so với trước bơm.

\section{BÀN LUÂNN}

Đặc điểm chung: Bệnh màng trong gặp cả nam và nữ, tỉ số nữ/nam là $1,1 / 1$. Nhiều nghiên cứu trên thế giới và trong nước đã chỉ ra rằng trẻ 
nam có nguy cơ mắc bệnh màng trong nhiều hơn trẻ nữ $[1][2][3]$. Tuổi thai trung bình là $30,1 \pm 3,1$ tuần. Sự phân bố tuổi thai trong nghiên cứu này tương tự với một số nghiên cứu trong và ngoài nước cưa Cherif $A{ }^{[1]}$, Phạm Nguyễn Tố Như và cộng sự [2]. Phần lớn đối tượng nghiên cứu có cân nặng phù hợp với tuổi thai chiếm tỷ lệ 84,2\%.

Đặc điểm lâm sàng, cận lâm sàng và một số yếu tố liên quan đến bệnh màng trong: Về nhịp thở, có $19,3 \%$ thở nhanh > 60 lần/phút và 3,5\% có cơn ngưng thở bệnh lý. Tím với $\mathrm{SpO}_{2}<90 \%$ $\mathrm{SpO}_{2}$ đo qua da giảm ở 40,4\% trẻ trong nhóm nghiên cứu. Nhu cầu $\mathrm{FiO}_{2}$ cung cấp cho trẻ lúc vào viện $\geq 30 \%$ chiếm $91,2 \%$. Và nhiều trẻ cần hỗ trợ thở CPAP hoặc thở máy ngay lúc vào viện. Mặc dù $\mathrm{FiO}_{2}$ trong khí thở vào cao và thở máy hỗ trợ nhưng trẻ vẫn chưa đạt được $\mathrm{SpO}_{2} \geq 90 \%$. Trong nghiên cứu của chúng tôi, triệu chứng này xuất hiện sớm ở nhiều trẻ, biểu hiện rõ rệt ở môi, đầu chi. Kết quả cũng đồng nhất với nghiên cứu của Trần Thị Thủy ${ }^{[4]}$. Tỷ lệ rút lõm lồng ngực chiếm 33,3\%, thở rên gặp ở 31,6\%. Trẻ sinh non trung tâm hô hấp chưa hoàn chỉnh vì vậy khả năng điều hòa nhịp thở của trẻ còn kém, đáp ứng với tình trạng thiếu oxy bằng cách tăng nhịp thở chỉ trong một thời gian ngắn và sau đó nhanh chóng dẫn đến cơn ngừng thở. Có 19,3\% trẻ thở nhanh và $3,5 \%$ trẻ thở chậm và có cơn ngừng thở.

Phân độ tổn thương bệnh màng trong trên $X$ Quang trước điêuu trị, nghiên cứu cho thấy độ tổn thương gặp nhiều nhất là độ III chiếm 49,1\%, độ IV chiểm $22.8 \%$. Phân độ tổn thương trên XQuang phản ánh mức độ của bệnh màng trong trong đó bệnh màng trong nặng tương ứng với phân độ III-IV. Kết quả nghiên cứu của chúng tôi tương tự kết quả một số tác giả trong

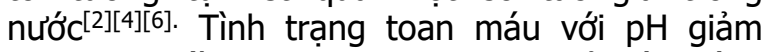
$(<7,25)$ chiếm $49,1 \%$. p $\mathrm{pO}_{2}$ tăng phản ánh tình trạng toan hô hấp, chúng tôi gặp 38,6\% trẻ có mức $\mathrm{pCO}_{2}$ cao trên $45 \mathrm{mmHg}$. Sự cải thiện trao đổi khí được thể hiện rõ sau bơm Surfactant.

Giới tính nam có liên quan đến mức độ nặng của bệnh màng trong trên X-Quang (độ III-IV), phù hợp với dịch tễ của bệnh màng trong là trè nam nhiều hơn trẻ nữ và tương tự kết quả của một số nghiên cứu khác. Các yếu tố khác như tuổi thai, cân nặng lúc sinh và tiền căn mẹ có điều trị corticoid trước sinh đều không có mối liên quan với mức độ nặng của bệnh.

Đặc điểm quá trình điều trị: nhiều nghiên cứu cho thấy sử dụng Surfactant càng sớm thì hiệu quả càng cao. Trong nghiên cứu của chúng tôi, thời gian từ khi sinh đến khi điều trị là 3 giờ ngắn hơn so với nghiên cứu của Trần Thị Bích Phượng [3] là 12,71 giờ, Phạm Nguyễn Tố Như [2] là 9,4 giờ. Theo hướng dẫn của đồng thuận châu Âu trong quản lý bệnh màng trong năm 2019, liều Surfactant thay thế là Poractant alfa 200 $\mathrm{mg} / \mathrm{kg}$ ở liều khởi đầu và liều thứ hai thậm chí liều thứ ba của Surfactant nếu có bằng chứng của bệnh màng trong diễn tiến (mức chứng cứ 1A). Trong nghiên cứu của chúng tôi, chế phẩm Surfactant được sử dụng là Curosulf $120 \mathrm{mg} / 1,5 \mathrm{~mL}$. Liều bơm trung bình: liều 1 là $179,9 \mathrm{mg} / \mathrm{kg}$; liều 2 cho 7 trẻ chiếm tỷ lệ 12,3\% do không giảm được nhu cầu oxy trên lẩm sàng và X-Quang cải thiện kém sau bơm Surfactant lần 1 , liều trung bình liều 2 là $134 \mathrm{mg} / \mathrm{kg}$. Chúng tôi tiến hành bơm Surfactant bằng hai phương pháp qua nội khí quản sau đó thở máy và phương pháp INSURE. Tỷ lệ trẻ được thực hiện bằng phương pháp thở máy sau bơm $(68,4 \%)$ và số trẻ thực hiện INSURE thất bại - phải đặt nội khí quản lại trong vòng 72 giờ sau bơm $(12,3 \%)$ Tỷ lệ trẻ thực hiện INSURE thành công chiếm tỷ lệ 19,3\%. Tất cả các trẻ thực hiện bớm Surfactant lần 2 đều được thở máy sau bơm, không có ca nào thực hiện INSURE.

Nồng độ $\mathrm{FiO}_{2}$ sau điều trị Surfactant 1 giờ, 6 giờ và 24 giờ đều giảm có ý nghĩa thống kê so với trước điều trị với giá trị $p<0,05$. Tương tự với nghiên cứu của Trần Thị Bích Phượng [3], Phạm Nguyễn Tố Như, Lâm Thị Mỹ ${ }^{[2]} \mathrm{FiO}_{2}$ giảm ở 1 giờ và 24 giờ sau bơm Surfactant. Tương tự với Ramathan $\mathrm{R}$ và cộng sự [7] điều trị bệnh màng trong với Curosurf, $\mathrm{FiO}_{2}$ giảm sau bơm 1 giờ và 6 giờ.

Xquang sau bơm Surfactant 6 giờ trong nghiên cứu của chúng tôi cho thấy cải thiện $96,5 \%$. Tương tự kết quả của Trân Thị Bích Phượng ${ }^{[3]}$ với $80 \%$ cải thiện trên X-Quang lúc 6 giờ, và Phạm Nguyễn Tố Như, Lâm Thị Mỹ [2] với X-Quang phổi bệnh màng trong độ III, IV giảm từ $93,3 \%$ xuống $0 \% 48$ giờ sau bơm.

Tỷ lệ sống của nghiên cứu chúng tôi là $80 \%$; chuyển tuyến trên $15,8 \%$. Nghiên cứu của Trần Thị Bích Phượng ${ }^{[12]}$ là $(85,7 \%)$ và Phạm Nguyễn Tố Như, Lâm Thị Mỹ [2] là (83,3\%). Nguyên nhân tử vong trong nghiên cứu của chúng tôi do nhiễm trùng huyết nặng gây sốc nhiễm trùng chiếm tỷ lệ $58,3 \%$; viêm ruột hoại tử có biến chứng kết hợp sốc nhiễm trùng chiếm $25 \%$ và ít gặp hơn là xuất huyết phổi. Đặc biệt trong số các trẻ tử vong của chúng tôi có 1 trẻ tử vong do biến chứng xuất huyết phổi ngay sau bơm Surfactant lần 1 và 2 trẻ không đáp ứng sau 2 lân bơm Surfactant. Theo Fujiwara [7] tử vong chủ yếu do xuất huyết não, tràn khí màng phổi. 
Phạm Nguyễn Tố Như, Lâm Thị Mỹ [2] tử vong là khổng đáp ứng với bơm Surfactant và nhiễm trùng sơ sinh. Nguyễn Viết Đồng [6], tử vong do suy hô hấp (50\%) và xuất huyết phổi $(33,3 \%)$, nhiễm trùng huyết $6,7 \%$.

Chúng tôi, 46 ca thở máy không xâm nhập NCPAP/NIPPV với thời gian trung vị là 6 ngày. Theo Nguyễn Viết Đồng [6] là 5,1 ngày. Các biến chứng gôm: tràn khí màng phổi $(5,3 \%)$, xuất huyết phổi $(5,3 \%)$ và hạ huyết áp hệ thống $(15,8 \%)$ tương tự kết quả của một số nghiên cứu trong nước khác ${ }^{[6][2] . ~}$

\section{KẾT LUÂ̂N}

Điêu trị Surfactant thay thế ở trẻ sơ sinh non tháng bị bệnh màng trong tại Bệnh viện Sản-Nhi Quảng Ngã̃i đem lại hiệu quả lâm sàng rõ rệt, giảm nhu câu Oxy sau bơm thuốc 1 giờ, $X-$ Quang phổi cải thiện $96,5 \%$ sau 6 giờ bơm thuốc. Bệnh có liên quan đến giới tính nam.

\section{TÀI LIÊU THAM KHẢO}

1. Pham Nguyễn Tố Nhứ, Lâm Thị Mỹ (2010), "Mổ tả kết quả điều trị bênh màng trong ở tré sanh non bằng Surfactant qua kỹ thuật INSURE", Tạp chí $Y$ học thành phố Hồ Chí Minh, 1(14)', tr.155-161.
2. Trân Thị Bích Phượng, Trân Tôn Nữ Anh Ty (2012), "Đánh giá hiệu quả điều trị Surfactant trong điêu trị bệnh màng trong ở trẻ sinh non tại khoa hồi sức cấp cứu Bệnh viện Nhi Đồng Nai", Đề tài cấp tỉnh năm 2012.

3. Trân Thị Thủy, Ngô Thị Xuân (2017), "Kết quả phương pháp INSURE trong điều trị hội chứng suy hô hấp ở trẻ đẻ non tại Bệnh viện Sản Nhi Bắc Ninh năm 2017 ", Tap chí Khoa học ĐHQGHN: Khoa hoc Y Dước, 33(2), tr.106-114.

4. Nakhshab $M$, Tajbakhsh $M$, Khani $S$, et al (2015), "Comparison of the effect of Surfactant administration during nasal continuous positive airway pressure with that of nasal continuous positive airway pressure alone on complications of respiratory distress syndrome: a randomized controlled study", Pediatrics \& Neonatology, 56 (2), pp. 88-94.

5. Nguyê̂n Viết Đồng, và cs (2018). Nghiên cứu điểu trị bệnh màng trong ở trẻ đẻ non bằng liệu pháp Surfactant tại Khoa Nhi - Bệnh viện đa khóa tỉnh Hà Tỉnh.

6. Fujiwara T, Chida S, Watabe Y, et al (1980), "Artificial Surfactant therapy in hyaline-membrane disease", The Lancet, 315 (8159), pp.55-59.

7. Ramathan R, Rsmussen MR, Gerstmann D, et al (2004) "A randomized, multicenter masked comparison trial of Curosuff versus Survanta in the treatment of respiratory distress syndrome in preterm infant", AJP, 21(3), pp.109- 119.

\title{
KẾT QUẢ BAN ĐẦU CỦA PHẪU THUÂTT ĐIỀU TRI LỖ HOÀNG ĐIỂM DO CHẤN THƯƠNG ĐỤNG DẬP NHÃN CẦU
}

\author{
Nguyễn Minh Thi ${ }^{1}$, Đỗ Như Hơn' ${ }^{1}$, \\ Thẩm Trương Khánh Vân ${ }^{2}$, Nguyễn Thái Đạt ${ }^{2}$
}

\section{TÓM TẮT}

Lỗ hoàng điểm do chấn thương đụng dập nhãn cầu là một bệnh lý nặng, ảnh hưởng nghiêm trọng đến chức năng thị giác. Cho đến nay, phâuu thuật cắt dich kính, bóc màng ngăn trong, độn khí nở nội nhãn vẫn được áp dụng cho những trường hợp lỗ hoàng điểm chấn thưởng không tự đóng và mang đến kễt quả khả quan. Tuy nhiên những báo cáo về kết quả điều trị lô̂́ hoàng điểm chấn thương còn lẻ tẻ và chủ yếu được thực hiện trên các nhóm bệnh nhân nhỏ. Mục tiêu nghiên cứu nhằm mô tả một số kết quả ban đầu của phẫu thuật điều trị lỗ hoàng điểm do chấn thương đụng dập nhãn cầu. Nghiên cứu mô tả được tiến hành trên 33 mắt có lỗ hoàng điểm do chẩn

1 Trường Đại học Y Hà nội

²Bệnh viện Mắt Trung ương

Chịu trách nhiệm chính: Nguyễn Minh Thi

Email: nguyenminhthi.vnio@gmail.com

Ngày nhận bài: 3.3.2021

Ngày phản biên khoa học: 23.4.2021

Ngày duyệt bài: 4.5.2021 thương đụng dập nhãn câu. Kết quả cho thây $81,8 \%$ nhóm nghiên cứu thành công đóng lỗ hoàng điểm sau một đễn hai lần phẫu thuật. 57,6\% các trưỡng hợp đóng lỗ hoàng điểm type 1 và $24,2 \%$ đóng lố hoàng điểm type 2. Có $27,3 \%$ tổng số bệnh nhân cần đến phẫu thuât lần hai sau phẩu thuật lần đầu tiên lỗ hoàng điểm không đóng. Trong nhóm này, tỉ lệ đóng lố hoàng điểm chỉ đạt $44,44 \%$ với tỉ lệ đóng lố hoàng điểm type 1 sau mổ rất thấp chỉ đạt $11,11 \%$. Sau phẫu thuật 3 tháng, 45,5\% số bệnh nhân có cải thiện thị lực tự 2 dòng Snellen trở lên. Chiêu dày trung tâm hoàng điểm và vùng ellipsoid sau phẫu thuật giảm nhẹ so với trước phẫu thuật, không có ý nghĩa thống kê. Với những trường hợp đóng lỗ hoàng điểm type 2 sau phẫu thuật, kích thước đáy lỗ hoàng điểm có thu hẹp so với trước phẫu thuật $(p<0,05)$.

Tư khóa: Lố hoàng điểm, chấn thương đụng dập nhãn cầu

\section{SUMMARY \\ THE EARLY RESULT FOR TREATMENT OF TRAUMATIC MACULAR HOLE DUE TO BLUNT TRAUMA}

